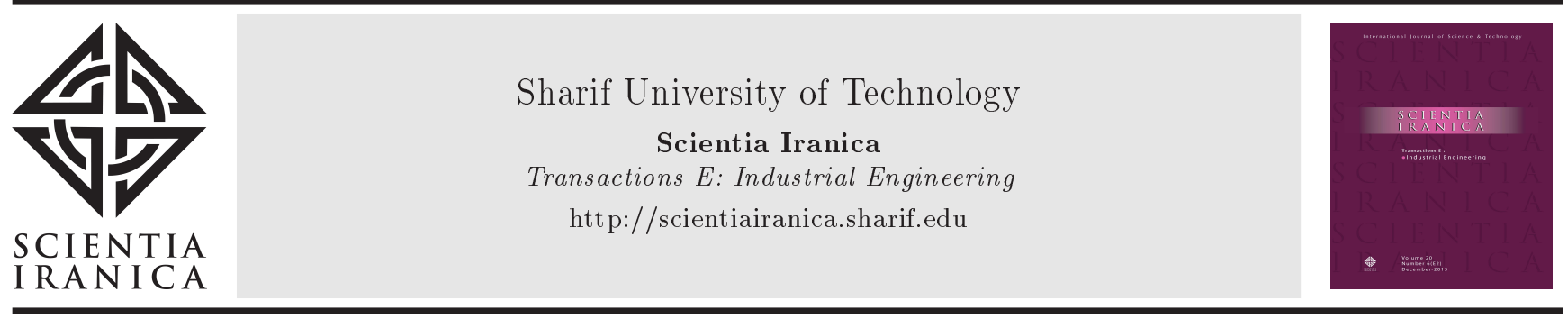

\title{
Cooperative advertising with two local advertising options in a retailer duopoly
}

\author{
S. Alaei* and N. Manavizadeh \\ Department of Industrial Engineering, Khatam University, Tehran, Iran.
}

Received 19 June 2019; received in revised form 7 February 2020; accepted 2 November 2020

\section{KEYWORDS}

Cooperative

advertising;

Game theory;

Advertising options;

Retail competition;

Equilibrium solution.

\begin{abstract}
This paper investigates cooperative advertising with local advertising options in a channel with three players including a manufacturer and two retailers. The current study applied the cooperative advertising literature to a case with two options for local advertising investment. To this end, this paper compared two cases of the presence and absence of cooperative advertising, which has almost been neglected in the cooperative advertising literature. The objective of this study is to determine the equilibrium strategy of the retailers' advertising options, players' advertising expenditures, and manufacturers' participation rates on retailers' investment. The aforementioned problem was analyzed as a three-stage game using backward induction. In the first and second stages, advertising investments of players were analytically determined. In the third stage, the Nash equilibrium pair of advertising options was found through numerical studies. The problem was solved by illustrative examples in two cases of the presence and absence of the cooperative advertising contract. Finally, the conditions for which offering the contract was win-win for all players were identified. Sensitivity analysis was carried out to explain the efficacy of the model.
\end{abstract}

(C) 2022 Sharif University of Technology. All rights reserved.

\section{Introduction}

Supply chain members may behave as part of a unified system and coordinate with each other to improve the overall efficiency of supply chain; hence, "coordination" comes into focus [1]. Supply chain coordination is the vehicle between channel members to redesign decision rights, workflow, and resources to get higher profit margins, improved customer service performance, and faster response time [2]. Retail fixed markup [3], buyback [4], revenue sharing [5], and quantity discount [6] are among the widely used coordination contracts in practice.

\footnotetext{
*. Corresponding author. Tel.: +982189174114 E-mail addresses: s.alaei@khatam.ac.ir (S. Alaei); n.manavi@khatam.ac.ir (N. Manavizadeh)
}

Vertical cooperative (co-op) advertising introduced by Berger [7] is typically a cost-sharing mechanism and advertising coordination scheme adopted by manufacturers to influence the behavior of their retailers. While manufacturers advertise to promote the brand of their products, retailers locally advertise to achieve short-term sales [8]. In a cooperative advertising program, manufacturer's participation in paying a fraction of local advertising costs increases the retailer's incentive to invest more in advertising and, consequently, achieve further sales. This participation is often expressed as a percentage of the retailer's advertising costs [9]. Zhang et al. [10] demonstrated that although bilateral participation in cooperative advertising achieved channel coordination, traditional cooperative advertising might not lead to channel coordination. However, it may result in a better channel performance as well as win-win or Pareto efficient outcome for supply chain members. A contract 
is Pareto-efficient if all players in the supply chain are not worse off and, at least, one is strictly better off with the existing contract compared to any other contracts [11].

Manufacturers' participation in co-op advertising is nowhere near insignificant [12]. There are many reasons for such cooperation between the manufacturers and retailers. Hutchins [13] argued that manufacturers adopted cooperative advertising because the program would lead to a quick sale. While national advertising by the manufacturer creates a brand image that is more general than the retailers' advertising, the retailer's local advertising mostly affects the price and promotion of goods. As a result, national advertising focuses mostly on generalizing a product, but it does not necessarily lead to an actual demand [14]. Due to such supplementary effects, manufacturers are partly dependent on the retailer's advertising so that their local advertising may look unsatisfactory on behalf of the manufacturer [15]. Under such circumstances, the cooperative advertising program could act as an incentive policy to satisfactorily increase the level of local advertising as required.

Cooperative advertising is highly promoted in today's marketing practices. The budget allocated to local advertising of the GE Company is three times more than its national advertising budget [16]. Moreover, the costs associated with Intel's cooperative advertising increased from $\$ 800$ million in 1999 to $\$ 5.1$ billion in 2001 [17]. Companies such as IBM [18] and Apple [19] have also benefited from this mechanism. Small, online co-op advertising particularly exists in automotive and durable goods [12]. The interested readers may refer to "Co-op Advertising Programs Sourcebook" (available on www.co-opsourcebook.com) which lists thousands of available co-op programs in 52 product classifications. The categories range from agricultural products to toys. However, most companies arbitrarily set their participation rate without having an analysis and this, in return, emphasizes the need for analytic studies [20].

The present study discusses cooperative advertising with local advertising options in a channel with three players including a manufacturer and two retailers. The market demand is influenced by the players' advertising efforts. In addition, the retailers' market share depends on their selected local advertising options among which each of the retailer can only choose one for advertising. Aiming at maximizing profit, each player determines the optimal level of advertising investment. Moreover, the retailers in the downstream echelon of the supply chain set their advertising options. The equilibrium solution of the problem is determined by game theory in three stages.

According to "Co-op Advertising Programs Sourcebook", approximately $\$ 50$ billion of media ad- vertising (television, magazines, online, newspapers, radio, billboards, etc.) is financed through co-op programs. Most studies assume that there is only one advertising option available for retailers' advertising. However, different advertising options have different impacts on demand and market share. Clearly, in the case of ignoring the effect of advertising options in the problem, sub-optimal solutions would be obtained.

Most studies in the cooperative advertising literature assume the players' acceptance of this contract in a non-cooperative or cooperative framework. In the cooperative case, the problem is often analyzed through bargaining games and contract parameters set so that none of the players are worse off compared to the non-cooperative solution [21-24]. However, in most cases, some players may not be motivated enough to accept a non-cooperative contract. In other words, some players' profit in the absence of contract may be more than that in the case with a contract. In this regard, the present study examines two cases of the absence and presence of the cooperative advertising contract. Finally, the conditions for which cooperative advertising can benefit all players are identified.

This study is different from previous ones in several ways. First, this study attempts to examine the cooperative advertising problem with two advertising options. Each retailer decides on the optimal level of investment after selecting the appropriate option. Second, it takes into account the retailers' competition in the channel so that each competes for greater market share. The retailers' selected advertising options directly affect their market share, which is closer to the real-world assumptions. Third, this study compares two cases of presence and absence of cooperative advertising, which has almost been neglected in the cooperative advertising literature. Then, the necessary conditions for a win-win cooperative advertising contract are identified.

The rest of this paper is organized as follows. In Section 2, the related literature is reviewed. In Section 3, followed by introducing the symbols and market demand function, the profit functions of players are formulated. In Section 4, the defined problem is solved as a three-stage game for two cases of presence and absence of the cooperative advertising. In Section 5, the numerical results from two cases for the system variables and profits are discussed, and the necessary conditions for a win-win cooperative advertising contract are identified using sensitivity analysis. In Section 6, the concluding remarks and recommendations for future research are presented.

\section{Literature review}

In recent years, extensive studies have been conducted on cooperative advertising. For example, refer to 
the studies by Aust and Buscher [25] and Jørgensen and Zaccour [26] for a comprehensive review of the literature.

Most studies on cooperative advertising have considered monopoly at upstream/downstream echelon so that there is only one supplier/manufacturer located at the upstream echelon and only one retailer/purchaser at the downstream echelon $[22,27]$. However, a number of researchers have developed models of duopoly [2832] and oligopoly [33], in which rivals competed with each other to achieve greater benefits. The main focus of this study is on the models that consider a duopoly market.

Budgeting among different media alternatives is becoming an increasingly difficult marketing task mainly because each may have a different impact on market demand and market share. Of note, ignoring this issue may lead to sub-optimal solutions. Malthouse et al. [34] investigated a problem where an organization must choose among multiple media vehicles for a marketing campaign. They argued that different vehicles had different marginal costs per impression. Their model was solved to maximize profit. Different media such as television, radio, magazines, newspapers, billboards, cinema, etc. can differ widely in their shortand/or long-run effectiveness [35]. Naik and Peters [36] analyzed an advertising campaign for cars involving six media (television, magazines, newspapers, radio, internet banners, and sponsored search). They found that radio advertising was the most cost effective, followed by newspapers, TV, and magazines.

There are a few studies on cooperative advertising that investigate players' sufficient incentives to accept the contract. For example, Jorgensen et al. [37] examined dynamic advertising and promotional strategies in a retailer-manufacturer marketing channel. They compared stationary feedback equilibria for two noncooperative games, including Nash equilibrium without promotional support and stackelberg equilibrium with promotional support. According to their findings, the employed cooperative advertising support program was Pareto improvement. Yang et al. [38] compared the models with/without the cooperative advertising contract in a retailer-manufacturer channel. Although their model did include pricing decisions, retailers' fairness concern effect was taken into account. They identified the necessary conditions for perfect channel coordination when the retailer was involved with fairness concerns. Chen [39] and Giri and Bardhan [40] studied ordering and advertising decisions in a retailermanufacturer channel and proposed a profit-sharing contract. They also examined the presence and absence of the cooperative advertising contract. Since the contract did not provide sufficient incentives for channel members, another mechanism called channel rebates was suggested to obtain a win-win condition. Gou et al. [41] employed differential game theory to evaluate three scenarios including no cooperation, joint venture cooperation, and contractual alliance cooperation. They found that joint venture cooperation and contractual alliance cooperation were more profitable than non-cooperation. Karray and Hassanzadeh Amin [42] evaluated the effects of cooperative advertising in a channel with competing retailers. According to the obtained results, co-op advertising may not be profitable for the retailers or for the channel, especially when the market was characterized by low levels of price competition and high advertising competition among retailers. This study also compared the presence and absence of the cooperative advertising and identified the necessary conditions for the contract to be winwin.

\section{Description of the model}

The present research takes into account a two-level supply chain where a manufacturer at the first level sells a product through two retailers at the second level. The market demand function is deterministic which is affected by advertising expenditures of the members. The manufacturers advertise nationally to promote the brand name of their products, while the two retailers advertise locally to achieve short-term sales and greater market share. Each retailer can choose between two available advertising options: each of these options has a different impact on the market share.

The purpose of the model is to determine optimal decision variables for each player. In other words, to maximize their profits, the retailers first select the appropriate advertising options and, then, make decisions about the optimal level of investment in the selected option. The profit function depends on the market share, profit margin, market demand, and associated advertising costs. The following symbols are frequently used throughout this paper:

\section{Parameters}

$J \quad$ The set of local advertising options for each retailer: $J=\{1,2\}$

$i, j \quad$ Retailers' local advertising options

$\Omega \quad$ The set of retailers' pairs of local advertising options. $\Omega=$ $\{(1,1),(1,2),(2,1),(2,2)\}$

$(i, j) \quad$ The pair of local advertising options where retailers 1 and 2 select $i$ and $j$, respectively: $(i, j) \in \Omega$

$k_{m} \quad$ The efficiency coefficient of national advertising in the market demand

$k_{i} \quad$ The efficiency coefficient of local advertising option $i$ in demand 
$c_{i}$

$C$

$\rho_{m}$

$\rho_{1}, \rho_{2}$

$\eta_{i j}$

$\Pi_{m \mid(i, j)}$

$\Pi_{1 \mid(i, j)}$

$\Pi_{2 \mid(i, j)}$

$D\left(A, a_{i}, b_{j}\right)$ Market demand function for pair $(i, j)$

\section{Decision variables}

A

Manufacture's national advertising level

$a_{i \mid(i, j)} \quad$ Local advertising level for retailer 1 in advertising option $i$ for pair $(i, j)$

$b_{j \mid(i, j)} \quad$ Local advertising level for retailer 2 in advertising option $j$ for pair $(i, j)$

$t_{1}^{i j} \quad$ The participation rate of manufacturer in the advertising of retailer 1 for pair $(i, j)$

$t_{2}^{i j} \quad$ The participation rate of manufacturer in the advertising of retailer 2 for pair $(i, j)$

Figure 1 shows the product flow as well as the financial flow in the channel. Our analysis in this paper takes some assumptions and definitions into account, as described in the following:

Assumption 1. The value of participation rates in the proposed cooperative advertising program varies between 0 and 1 ; hence, negative participation rates are not reasonable;
Table 1. Representation of $G(\eta)$, the $\eta$-specific game.

$$
\begin{array}{lll} 
& \multicolumn{1}{c}{\mathbf{1}} & \mathbf{2} \\
\cline { 2 - 3 } \mathbf{1} & \Pi_{1 \mid(1,1)}(0.5), \Pi_{2 \mid(1,1)}(0.5) & \Pi_{1 \mid(1,2)}(\eta), \Pi_{2 \mid(1,2)}(1-\eta) \\
\mathbf{2} & \Pi_{1 \mid(2,1)}(1-\eta), \Pi_{2 \mid(2,1)}(\eta) & \Pi_{1 \mid(2,2)}(0.5), \Pi_{2 \mid(2,2)}(0.5) \\
\cline { 2 - 2 } &
\end{array}
$$

Assumption 2. Retailers have credible information exchange regarding the profit functions and profit margins.

Definition 1: The $\eta$-specific game. Assume that if retailers choose the same advertising options, either $(1,1)$ or (2,2) regardless of the value of $\eta$, the market is equally shared between them. However, if they choose different advertising options, either (1,2) or (2,1), the market share of retailer who chooses option 1 is $\eta$ and that of another retailer is $1-\eta$. We denote this game by $G(\eta)$, as given in Table 1 .

Definition 2: Win-win strategy. We say that the strategy s leads to a win-win condition over the strategy $s^{\prime}$; if for all $k \in\{1,2, m\}$, it is the case that $\Pi_{k}^{s} \geq \Pi_{k}^{s^{\prime}}$, and at least for one $k^{\prime} \in\{1,2, m\}$, we have $\Pi_{k^{\prime}}^{s}>$ $\Pi_{k^{\prime}}^{s^{\prime}}$. Note that 1, 2, and $m$ correspond to retailer 1 , retailer 2 , and manufacturer, respectively.

This study specifies a win-win condition for cooperative advertising contract. Therefore, the strategies $s$ and $s$ ' correspond to the presence and absence of contract.

\subsection{Market demand function}

The market demand function is assumed to be affected by the retailers' local advertising and the manufacturer's national advertising. The effect of price on the demand is ignored and pricing decisions are not taken into account. This assumption has been discussed in several studies such as $[8,38,43]$. The market demand function for any pair of advertising options $(i, j)$ is obtained from Eq. (1):

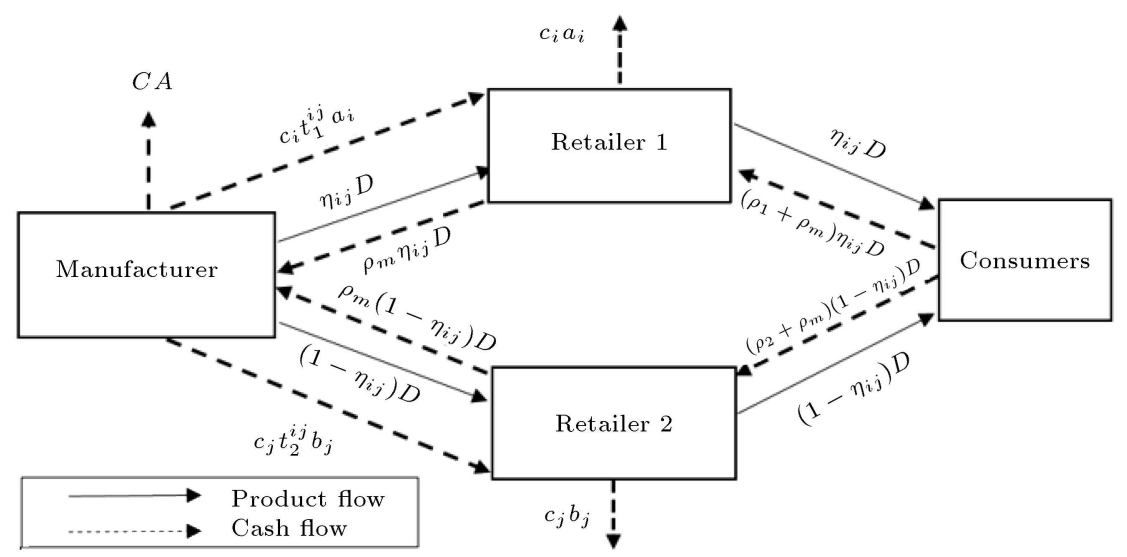

Figure 1. Product flows and financial flows among players when the retailers choose the pair $(i, j)$. 


$$
\begin{aligned}
& D\left(a_{i}, b_{j}, A \mid(i, j) \in \Omega\right)=k_{i} \sqrt{a_{i \mid(i, j)}}+k_{j} \sqrt{b_{j \mid(i, j)}} \\
& \quad+k_{m} \sqrt{A}
\end{aligned}
$$

The above demand function was used by Dust and Bushcher [31] for retailers' duopoly. However, their model did not include advertising options. Likewise, in this study, the retailers' advertising efficiency was considered equal because they believed that this parameter mostly depended on the impressibility of the customers rather than the behavior of retailers.

\subsection{Objective functions of players}

As previously noted, each retailer faces two available advertising options, and each can select one. Each retailer's profit depends on his market share, which itself is dependent on his and the rival retailer's advertising options. Based on the defined market demand function and retailers' market share, the profit functions can be formulated. Eqs. (2), (3), and (4) show the profit functions of manufacturer, retailers 1 and 2 , respectively.

$$
\begin{aligned}
\Pi_{m \mid(i, j)}= & \rho_{m}\left(k_{i} \sqrt{a_{i \mid(i, j)}}+k_{j} \sqrt{b_{j \mid(i, j)}}+k_{m} \sqrt{A}\right) \\
& -t_{1}^{i j} c_{i} a_{i \mid(i, j)}-t_{2}^{i j} c_{j} b_{j \mid(i, j)}-C A \\
\Pi_{1 \mid(i, j)}= & \rho_{1} \eta_{i j}\left(k_{i} \sqrt{a_{i \mid(i, j)}}+k_{j} \sqrt{b_{j \mid(i, j)}}+k_{m} \sqrt{A}\right) \\
& -\left(1-t_{1}^{i j}\right) c_{i} a_{i \mid(i, j)}, \\
\Pi_{2 \mid(i, j)}= & \rho_{2}\left(1-\eta_{i j}\right)\left(k_{i} \sqrt{a_{i \mid(i, j)}}+k_{j} \sqrt{b_{j \mid(i, j)}}+k_{m} \sqrt{A}\right) \\
& -\left(1-t_{2}^{i j}\right) c_{j} b_{j \mid(i, j)} .
\end{aligned}
$$

In Eq. (2), the first term (the product of profit margin and total demand) is the profit from sale; the second and third terms represent the participation in retailer 1 and 2's advertising cost, respectively, and the fourth term is the national advertising cost. In Eqs. (3) and (4), the first and second terms represent the profit from the sale and retailers' advertising costs, respectively.

\section{Solution approach}

Game theory is a commonly used method in the literature to analyze the issue of cooperative advertising [26]. This study evaluates the behavior of the players using non-cooperative games, in which each player makes decisions independently with the objective of optimizing his/her objective. In case the cannel members have equal power, they make their decisions independently and simultaneously with the objective of optimizing their objectives. In this case, Nash equilibrium offers the desired solution [44], in which none of the players precede the others in terms of decision-making. However, in a leadership Stackelberg game, players are divided into leaders and followers. This game is based on sequential decision-making and usually, it begins when some players have a certain privilege that allows them to move first. In a channel, the more powerful party might be the leader. The game is played in two stages: First, the leader chooses his strategy and then, the follower determines his strategy with regard to the leader's strategy [45]. Manufacturers have mostly been treated as the leaders and retailers as the followers of the Stackelberg game in the cooperative advertising literature [25].

\subsection{The sequence of events and decision-making}

The sequence of events has a remarkable effect on the sequence of decisions and type of game between players. The sequence of events in the problem is as follows: First, the manufacturer announces the level of national advertising investment as well as the participation rates to retailers. As a result, $\left\{A, t_{1}^{i j}, t_{2}^{i j} \mid(i, j) \in\right.$ $\Omega\}$ is proposed to the retailers. Second, according to the manufacturer's announced values, the retailers determine their best solution $\left(a_{i}, b_{j}\right)$ for each pair of advertising options $(i, j) \in \Omega$ and choose the best $\left(i^{*}, j^{*}\right)$ based on all pairs' outcome. Of note, the retailers' decision-making on the downstream echelon is performed in a bi-level form. Each retailer first chooses an advertising option and, then, determines the amount of investment in the selected option. The next two subsections offer a solution to the presence and absence of cooperative advertising contract, respectively.

\subsection{The manufacturer offering cooperative advertising}

According to the previous section, backward induction was employed to determine the equilibrium solution. The solution stages are as follows:

- The first stage: For an arbitrary amount of the national advertising, participation rates, and any pair of advertising options $(i, j)$, the best response function of retailers is obtained. The retailers play a Nash game to determine local advertising expenditures for each pair $(i, j)$;

- The second stage: By substituting the retailers' best responses in the manufacture's objective function for any pair $(i, j)$, the optimal national advertising expenditure and participation rates are determined, as the manufacturer offers $\left\{A, t_{1}^{i j}, t_{2}^{i j} \mid(i, j) \in \Omega\right\}$ values knowing the retailer's best responses;

- The third stage: With regard to the retailers' outcome for any pair $(i, j) \in \Omega$, they simultaneously decide on an equilibrium pair of advertising options. 
Each stage of the solution is described in the following.

\section{The first stage}

In the first stage, it is assumed that retailers 1 and 2 have selected advertising options $i$ and $j$, respectively, where $(i, j) \in \Omega$. It is also assumed that the manufacturer has announced the values of national advertising and participation rates as $\left\{A, t_{1}^{i j}, t_{2}^{i j} \mid(i, j) \in \Omega\right\}$. Here, the objective is to find each retailer's best response according to these two assumptions. Therefore, the necessary conditions are obtained through derivation of Eqs. (3) and (4) with respect to variables $a_{i \mid(i, j)}$ and $b_{j \mid(i, j)}$, respectively:

$$
\begin{aligned}
\frac{\partial \Pi_{1 \mid(i, j)}}{\partial a_{i \mid(i, j)}}=0 & \Rightarrow \rho_{1} \eta_{i j}\left(\frac{k_{i}}{2 \sqrt{a_{i \mid(i, j)}}}\right)-\left(1-t_{1}^{i j}\right) c_{i}=0, \\
\frac{\partial \Pi_{2 \mid(i, j)}}{\partial b_{j \mid(i, j)}}= & \Rightarrow \Rightarrow \rho_{2}\left(1-\eta_{i j}\right)\left(\frac{k_{j}}{2 \sqrt{b_{j \mid(i, j)}}}\right) \\
& -\left(1-t_{2}^{i j}\right) c_{j}=0 .
\end{aligned}
$$

By solving Eqs. (5) and (6), Proposition 1 can be obtained.

Proposition 1. In the presence of cooperative advertising, for any pair of advertising options $(i, j) \in$ $\Omega$ and arbitrary values of national advertising and participation rates $\left\{A, t_{1}^{i j}, t_{2}^{i j} \mid(i, j) \in \Omega\right\}$, the retailers' best responses will be as follows:

$$
\begin{aligned}
& a_{i \mid(i, j)}=\left(\frac{\rho_{1} \eta_{i j} k_{i}}{2 c_{i}\left(1-t_{1}^{i j}\right)}\right)^{2}, \\
& b_{j \mid(i, j)}=\left(\frac{\rho_{2}\left(1-\eta_{i j}\right) k_{j}}{2 c_{j}\left(1-t_{2}^{i j}\right)}\right)^{2} .
\end{aligned}
$$

It should be noted that the objective functions of retailers 1 and 2 are concave with respect to variables $a_{i \mid(i, j)}$ and $b_{j \mid(i, j)}$ since:

$$
\begin{aligned}
& \frac{\partial^{2} \Pi_{1 \mid(i, j)}}{\partial a_{i \mid(i, j)^{2}}}=-\frac{\rho_{1} \eta_{i j} k_{i}}{4 \sqrt{a_{i \mid(i, j)}^{3}}}<0, \\
& \frac{\partial^{2} \Pi_{2 \mid(i, j)}}{\partial b_{j \mid(i, j)^{2}}}=-\frac{\rho_{2}\left(1-\eta_{i j}\right) k_{j}}{4 \sqrt{b_{j \mid(i, j)}^{3}}}<0 .
\end{aligned}
$$

\section{The second stage}

In this stage, the manufacturer must determine the optimal value of national advertising investment and participation rates considering the retailers' best responses in Proposition 1. Therefore, the maximization problem of the manufacturer according to Eq. (2) and Proposition 1 will be as follows:

$$
\begin{aligned}
\max _{A_{i j}, t_{1}^{i j}, t_{2}^{i j}} \Pi_{m \mid(i, j)}= & \rho_{m}\left(k_{i} \sqrt{a_{i \mid(i, j)}}+k_{j} \sqrt{b_{j \mid(i, j)}}\right. \\
& \left.+k_{m} \sqrt{A}\right)-t_{1}^{i j} c_{i} a_{i \mid(i, j)} \\
& -t_{2}^{i j} c_{j} b_{j \mid(i, j)}-C A
\end{aligned}
$$

s.t.:

$$
\begin{aligned}
& a_{i \mid(i, j)}=\left(\frac{\rho_{1} \eta_{i j} k_{i}}{2 c_{i}\left(1-t_{1}^{i j}\right)}\right)^{2}, \\
& b_{j \mid(i, j)}=\left(\frac{\rho_{2}\left(1-\eta_{i j}\right) k_{j}}{2 c_{j}\left(1-t_{2}^{i j}\right)}\right)^{2}, \\
& t_{1}^{i j}, t_{2}^{i j} \geq 0,
\end{aligned}
$$

where the constraints are the best response of retailers that can be easily substituted in the objective function. The necessary conditions for the optimality of the above function are obtained through its derivation to variables $A, t_{1}^{i j}$, and $t_{2}^{i j}$, as shown in the following:

$$
\begin{aligned}
& \frac{\partial \Pi_{m \mid(i, j)}}{\partial A}=0 \Rightarrow \frac{\rho_{m} k_{m}}{2 \sqrt{A}}-C=0 \\
& \frac{\partial \Pi_{m \mid(i, j)}}{\partial t_{1}^{i j}}=0 \Rightarrow \frac{\rho_{m} k_{i}}{1-t_{1}^{i j}} \frac{\rho_{1} \eta_{i j} k_{i}}{2 c_{i}\left(1-t_{1}^{i j}\right)} \\
&-c_{i}\left(\frac{\rho_{1} \eta_{i j} k_{i}}{2 c_{i}\left(1-t_{1}^{i j}\right)}\right)^{2}\left(\frac{1+t_{1}^{i j}}{1-t_{1}^{i j}}\right)=0 \\
& \frac{\partial \Pi_{m \mid(i, j)}}{\partial t_{2}^{i j}}=0 \Rightarrow \frac{\rho_{m} k_{j}}{1-t_{2}^{i j}} \frac{\rho_{2}\left(1-\eta_{i j}\right) k_{j}}{2 c_{j}\left(1-t_{2}^{i j}\right)} \\
&-c_{j}\left(\frac{\rho_{2}\left(1-\eta_{i j}\right) k_{j}}{2 c_{j}\left(1-t_{2}^{i j}\right)}\right)^{2}\left(\frac{1+t_{2}^{i j}}{1-t_{2}^{i j}}\right)=0
\end{aligned}
$$

Through simultaneous solving of Eqs. (10)-(12), the optimal values for variables can be calculated and the optimal local advertising investments are determined by substituting them into Proposition 1. Proposition 2 summarizes the results.

Proposition 2. In the presence of cooperative advertising, for any pair of local advertising options $(i, j) \in \Omega$, the equilibrium solution is as follows:

$$
\text { If } 2 \rho_{m}-\rho_{1} \eta_{i j} \geq 0 \text { and } 2 \rho_{m}-\rho_{2}\left(1-\eta_{i j}\right) \geq 0 \text { : }
$$




$$
\begin{aligned}
& t_{1}^{i j}=\frac{2 \rho_{m}-\rho_{1} \eta_{i j}}{2 \rho_{m}+\rho_{1} \eta_{i j}}, \\
& t_{2}^{i j}=\frac{2 \rho_{m}-\rho_{2}\left(1-\eta_{i j}\right)}{2 \rho_{m}+\rho_{2}\left(1-\eta_{i j}\right)}, \\
& A=\left(\frac{\rho_{m} k_{m}}{2 C}\right)^{2}, \\
& a_{i \mid(i, j)}=\left[\frac{k_{i}}{4 c_{i}}\left(2 \rho_{m}+\rho_{1} \eta_{i j}\right)\right]^{2}, \\
& b_{j \mid(i, j)}=\left[\frac{k_{j}}{4 c_{j}}\left(2 \rho_{m}+\rho_{2}\left(1-\eta_{i j}\right)\right)\right]^{2} .
\end{aligned}
$$

Otherwise, there is no feasible cooperative advertising contract.

Proof: According to Assumption 1, participation rates are assumed to be non-negative; hence, Proposition 2 is true until $2 \rho_{m}-\rho_{1} \eta_{i j} \geq 0$ and $2 \rho_{m}-\rho_{2}(1-$ $\left.\eta_{i j}\right) \geq 0$. This assumption is among the underlying assumptions and its violation is beyond the scope of this research. The sufficient conditions of optimality are provided in Appendix A.

\section{The third stage}

Each retailer chooses his advertising option with regard to his rival's advertising option based on his own and his rival's outcome (profit). Since both retailers have the same power in decision-making, they simultaneously and independently choose their own strategies. Therefore, the equilibrium pair of options could be determined by Nash equilibrium. Based on Proposition 2, each players' profit can be calculated, as summarized in Result 1.

Result 1. In the presence of cooperative advertising, for any pair of local advertising options $(i, j) \in \Omega$, the optimal profits of the players are:

$$
\begin{aligned}
\Pi_{m \mid(i, j)}= & \frac{k_{i}^{2}}{16 c_{i}}\left(2 \rho_{m}+\rho_{1} \eta_{i j}\right)^{2} \\
& +\frac{k_{j}^{2}}{16 c_{j}}\left(2 \rho_{m}+\rho_{2}\left(1-\eta_{i j}\right)\right)^{2}+\frac{\rho_{m}^{2} k_{m}^{2}}{4 C} \\
\Pi_{1 \mid(i, j)}= & \rho_{1} \eta_{i j}\left[\frac{k_{i}^{2}}{8 c_{i}}\left(2 \rho_{m}+\rho_{1} \eta_{i j}\right)\right. \\
& \left.+\frac{k_{j}^{2}}{4 c_{j}}\left(2 \rho_{m}+\rho_{2}\left(1-\eta_{i j}\right)\right)+\frac{\rho_{m} k_{m}^{2}}{2 C}\right],
\end{aligned}
$$

$$
\begin{aligned}
\Pi_{2 \mid(i, j)}= & \rho_{2}\left(1-\eta_{i j}\right)\left[\frac{k_{i}^{2}}{4 c_{i}}\left(2 \rho_{m}+\rho_{1} \eta_{i j}\right)\right. \\
& \left.+\frac{k_{j}^{2}}{8 c_{j}}\left(2 \rho_{m}+\rho_{2}\left(1-\eta_{i j}\right)\right)+\frac{\rho_{m} k_{m}^{2}}{2 C}\right] .
\end{aligned}
$$

Table 1 lists the retailers' profits for all available pairs of local advertising options, according to which the game equilibrium can be obtained. According to the theory of Nash equilibrium for a two-player game with $J$ being the set of each player's strategies, the strategies $\left(i^{*}, j^{*}\right)$ form a Nash equilibrium if and only if:

$$
\Pi_{l \mid\left(i^{*}, j^{*}\right)}=\max _{i \in J} \Pi_{l \mid\left(i, j^{*}\right)} \quad \forall l=1,2 .
$$

In other words, if retailer 1 selects a particular option (e.g., $i$ ), retailer 2 chooses his best response that provides him the highest profit. Similarly, retailer 1 has the same behavior. To find the equilibrium solution $\left(i^{*}, j^{*}\right)$, Result 1 should be employed to compute the game outcome and form the game, as given in Table 1. This stage is not analytically possible; therefore, the numerical examples in Section 5 are taken into account.

\subsection{The manufacturer does not offer cooperative advertising}

In this case, the manufacturer does not offer a cooperative advertising contract to the retailers; hence, each member incurs his or her own costs. The players' objective functions for this case are similar to those in Eqs. (2)-(4) as long as the participation rates are set to zero, i.e., $t_{1}^{i j}=t_{2}^{i j}=0$. Here, the manufacturer determines the value of national advertising investment, while the retailers make decisions to choose their advertising options and local advertising investment. Given that similar analysis needs to be performed for this case, only the main results of the problem are presented to avoid redundancy.

Proposition 3. In the absence of cooperative advertising, for any pair of local advertising options $(i, j) \in$ $\Omega$, the equilibrium solution is as follows:

$$
\begin{aligned}
& A=\left(\frac{\rho_{m} k_{m}}{2 C}\right)^{2}, \\
& a_{i \mid(i, j)}=\left(\frac{\rho_{1} \eta_{i j} k_{i}}{2 c_{i}}\right)^{2}, \\
& b_{j \mid(i, j)}=\left(\frac{\rho_{2}\left(1-\eta_{i j}\right) k_{j}}{2 c_{j}}\right)^{2} .
\end{aligned}
$$

It can be easily proved that the manufacturer's objective function is concave to $A$.

Result 2. In the absence of cooperative advertising, 
for any pair of local advertising options $(i, j) \in \Omega$, the optimal profits of the players are:

$$
\begin{aligned}
\Pi_{m \mid(i, j)}= & \rho_{m}\left(\frac{\rho_{1} \eta_{i j} k_{i}^{2}}{2 c_{i}}+\frac{\rho_{2}\left(1-\eta_{i j}\right) k_{j}^{2}}{2 c_{j}}+\frac{\rho_{m} k_{m}^{2}}{4 C}\right), \\
\Pi_{1 \mid(i, j)=} & \rho_{1} \eta_{i j}\left(\frac{\rho_{1} \eta_{i j} k_{i}^{2}}{4 c_{i}}+\frac{\rho_{2}\left(1-\eta_{i j}\right) k_{j}^{2}}{2 c_{j}}+\frac{\rho_{m} k_{m}^{2}}{2 C}\right), \\
\Pi_{2 \mid(i, j)=} & \rho_{2}\left(1-\eta_{i j}\right) \\
& \left(\frac{\rho_{1} \eta_{i j} k_{i}^{2}}{2 c_{i}}+\frac{\rho_{2}\left(1-\eta_{i j}\right) k_{j}^{2}}{4 c_{j}}+\frac{\rho_{m} k_{m}^{2}}{2 C}\right) .
\end{aligned}
$$

Similarly, we can find the equilibrium solution $\left(i^{*}, j^{*}\right)$, as described in the previous subsection. Note that the solution procedure can be easily generalized to an oligopoly case and that with multiple advertising options to retailers.

\section{Numerical study}

In this section, two examples of market configuration are considered for the problem that are presented in Table 2. There are two local advertising options for retailers: Television $(\mathrm{T})$ and Radio $(\mathrm{R})$. The manufacturer also uses television advertising for national advertising. It should be noted that television advertising is different on both national and local scales in terms of different costs and efficiencies since these parameters depend on advertising time and television channel. Given the value of $\eta$ in each case, $G(\eta)$ is played at the retailers' level. Note that according to Table 1 , in a game $G(\eta)$, we have $\eta_{11}=0.5, \eta_{12}=\eta$, $\eta_{21}=1-\eta$, and $\eta_{22}=0.5$.

\subsection{Detailed result of Example 1}

The detailed results for the absence and the presence of cooperative advertising contract are summarized in

Table 2. Market configuration for Examples 1 and 2.

\begin{tabular}{ccc}
\hline Parameter & Example 1 & Example 2 \\
\hline$\rho_{m}$ & 15 & 20 \\
$\rho_{1}$ & 10 & 10 \\
$\rho_{2}$ & 12 & 12 \\
$k_{m}$ & 100 & 100 \\
$k_{1}$ & 50 & 40 \\
$k_{2}$ & 50 & 50 \\
$C$ & 250 & 200 \\
$c_{1}$ & 20 & 30 \\
$c_{2}$ & 100 & 100 \\
$\eta$ & 0.4 & 0.4 \\
\hline
\end{tabular}

Table 3. The equilibrium of $G(0.4)$ in the absence of cooperative advertising.

\begin{tabular}{ccc} 
& $\mathbf{R}$ & $\mathbf{T}$ \\
\cline { 2 - 3 } $\mathbf{R}$ & $(3633,4280)$ & $(2573,4692)$ \\
$\mathbf{T}$ & $(3993,3067)$ & $\mathbf{( 3 0 3 1 , 3 6 0 0 )}$ \\
\cline { 2 - 3 }
\end{tabular}

Table 4. The equilibrium of $G(0.4)$ in the presence of cooperative advertising.

\begin{tabular}{ccc} 
& $\mathbf{R}$ & $\mathbf{T}$ \\
\cline { 2 - 3 } $\mathbf{R}$ & $(7067,8440)$ & $(4353,8886)$ \\
$\mathbf{T}$ & $(7447,5214)$ & $\mathbf{( 4 6 4 1 , 5 5 5 0 )}$ \\
\cline { 2 - 3 }
\end{tabular}

Tables 3 and 4, respectively. Obviously, the Nash equilibrium of each game is $(T, T)$. A comparison of the equilibrium of two cases revealed that the profit of each retailer increased by $54 \%$ by offering cooperative advertising.

The manufacturer's profit corresponding to the equilibrium solution to the absence and presence of cooperative advertising is 7750 and 11470 , which increases by $48 \%$. The values of variables are as follows:

- The national advertising $(A)$ is 25 seconds in both cases;

- In the equilibrium $(T, T)$ in the absence and presence of cooperative advertising, local advertising investment rates for Retailer 1 in television $\left(a^{T T}\right)$ are 1.5 and 31.6 seconds, respectively;

- In the equilibrium $(T, T)$ in the absence and presence of cooperative advertising, local advertising investment rates for retailer 2 in television $\left(b^{T T}\right)$ are 2.25 and 33 seconds, respectively;

- The manufacturer's participation rates in advertising for retailers 1 and $2\left(t_{1}^{T T}\right.$ and $\left.t_{2}^{T T}\right)$ are $77 \%$ and $74 \%$, respectively.

\subsection{Sensitivity analysis}

This section reports the sensitivity of the solutions to the changes in the value for parameters, and the changes in profits, percentage improvements upon offering the contract, and changes in the values of variables. Table 5 shows the results of sensitivity analysis of the market share $\eta$ which changes from 0.23 to 0.5 . The equilibrium and profits are computed for two cases of the absence and presence of contract. In the absence of contract, for $\eta \leq 0.44$, the equilibrium is $(T, T)$ and the profits are not sensitive to changes. Upon increasing the market share parameter, the equilibrium is changed to $(R, R)$ and profits increase. The similar shift occurs in the presence of contract when the market share changes from 0.41 to 0.44 . The percentage improvements of the profits upon offering contract are also reported in the last three columns of the table. According to the results, offering the contract always 
Table 5. Changes in profits with regard to changes in $\eta$.

\begin{tabular}{|c|c|c|c|c|c|c|c|c|c|c|c|c|}
\hline \multirow{2}{*}{ Problem \# } & \multirow{2}{*}{$k_{2}$} & \multicolumn{4}{|c|}{$\begin{array}{c}\text { Absence of } \\
\text { cooperative advertising }\end{array}$} & \multicolumn{4}{|c|}{$\begin{array}{c}\text { Presence of } \\
\text { cooperative advertising }\end{array}$} & \multicolumn{3}{|c|}{ Improvement (\%) } \\
\hline & & Eq. & $\Pi_{1}$ & $\Pi_{2}$ & $\Pi_{m}$ & Eq. & $\Pi_{1}$ & $\Pi_{2}$ & $\Pi_{m}$ & $\Pi_{1}$ & $\Pi_{2}$ & $\Pi_{m}$ \\
\hline 1 & 0.23 & $(T, T)$ & 3031 & 3600 & 7750 & $(T, T)$ & 4641 & 5550 & 11470 & 53 & 54 & 48 \\
\hline 2 & 0.26 & $(T, T)$ & 3031 & 3600 & 7750 & $(T, T)$ & 4641 & 5550 & 11470 & 53 & 54 & 48 \\
\hline 3 & 0.29 & $(T, T)$ & 3031 & 3600 & 7750 & $(T, T)$ & 4641 & 5550 & 11470 & 53 & 54 & 48 \\
\hline 4 & 0.32 & $(T, T)$ & 3031 & 3600 & 7750 & $(T, T)$ & 4641 & 5550 & 11470 & 53 & 54 & 48 \\
\hline 5 & 0.35 & $(T, T)$ & 3031 & 3600 & 7750 & $(T, T)$ & 4641 & 5550 & 11470 & 53 & 54 & 48 \\
\hline 6 & 0.38 & $(T, T)$ & 3031 & 3600 & 7750 & $(T, T)$ & 4641 & 5550 & 11470 & 53 & 54 & 48 \\
\hline 7 & 0.41 & $(T, T)$ & 3031 & 3600 & 7750 & $(T, T)$ & 4641 & 5550 & 11470 & 53 & 54 & 48 \\
\hline 8 & 0.44 & $(T, T)$ & 3031 & 3600 & 7750 & $(R, R)$ & 7067 & 8440 & 18803 & 133 & 134 & 143 \\
\hline 9 & 0.47 & $(R, R)$ & 3633 & 4280 & 10867 & $(R, R)$ & 7067 & 8440 & 18803 & 95 & 97 & 73 \\
\hline 10 & 0.5 & $(R, R)$ & 3633 & 4280 & 10867 & $(R, R)$ & 7067 & 8440 & 18803 & 95 & 97 & 73 \\
\hline
\end{tabular}

Table 6. Changes in variables with regard to changes in $\eta$.

\begin{tabular}{|c|c|c|c|c|c|c|c|c|c|}
\hline \multirow[t]{2}{*}{ Problem \# } & \multirow[t]{2}{*}{$\eta$} & \multicolumn{3}{|c|}{$\begin{array}{l}\text { Absence of } \\
\text { cooperative } \\
\text { advertising }\end{array}$} & \multicolumn{5}{|c|}{$\begin{array}{c}\text { Presence of } \\
\text { cooperative advertising }\end{array}$} \\
\hline & & $A$ & $a$ & $b$ & $t_{1}$ & $t_{2}$ & $A$ & $a$ & $b$ \\
\hline 1 & 0.23 & 25 & 1.6 & 2.3 & 0.78 & 0.74 & 25 & 31.6 & 33.1 \\
\hline 2 & 0.26 & 25 & 1.6 & 2.3 & 0.78 & 0.74 & 25 & 31.6 & 33.1 \\
\hline 3 & 0.29 & 25 & 1.6 & 2.3 & 0.78 & 0.74 & 25 & 31.6 & 33.1 \\
\hline 4 & 0.32 & 25 & 1.6 & 2.3 & 0.78 & 0.74 & 25 & 31.6 & 33.1 \\
\hline 5 & 0.35 & 25 & 1.6 & 2.3 & 0.78 & 0.74 & 25 & 31.6 & 33.1 \\
\hline 6 & 0.38 & 25 & 1.6 & 2.3 & 0.78 & 0.74 & 25 & 31.6 & 33.1 \\
\hline 7 & 0.41 & 25 & 1.6 & 2.3 & 0.78 & 0.74 & 25 & 31.6 & 33.1 \\
\hline 8 & 0.44 & 25 & 1.6 & 2.3 & 0.78 & 0.74 & 25 & 225 & 235.1 \\
\hline 9 & 0.47 & 25 & 11.1 & 16 & 0.78 & 0.74 & 25 & 225 & 235.1 \\
\hline 10 & 0.5 & 25 & 11.1 & 16 & 0.78 & 0.74 & 25 & 225 & 235.1 \\
\hline
\end{tabular}

improves the profit of members. Table 6 also shows the values of variables in both cases of the absence and presence of the contract. National advertising in both cases is independent of the market share parameter that does not change with the changes in this parameter. Participation rates also do not change mainly because despite the dependency of these variables on the market share parameter, the market share of each retailer is 0.5 and these variables do not change since the equilibrium is either $(R, R)$ or $(T, T)$. Local advertising variables increased only with a change in the equilibrium.

Table 7 shows the results of the sensitivity analysis of television advertising cost, $c_{2}$, which changes from 15 to 105 . The equilibrium in both cases is $(T, T)$. Since the equilibrium does not change with a change in $c_{2}$, based on the profit function of members, it is expected that upon increasing this parameter, the profits will decrease. The results given in this table confirm our expectation. The results also show that offering the contract always improves the profit of members. Problem variables are also shown in Table 8. The national advertising and participation rates are constant for the same reasons as described for $\eta$. Given that both retailers use television advertising in the equilibrium, upon increasing $c_{2}$, local advertising variables would decrease, thus confirming our expectations.

Tables 9 and 10 present the results of sensitivity analysis of the efficiency of television advertising, $k_{2}$. The equilibrium in the absence of contract is always $(T, T)$; however, it changes in the presence of contract. Upon increasing $k_{2}$ when the equilibrium is $(T, T)$, the profits and local advertising variables would increase, which is in line with our expectation. However, when the equilibrium is $(R, R)$, the profits and local advertising variables do not undergo any changes. The results also suggest that offering the contract always improves the profit of members. 
Table 7. Changes in profits with regard to changes in $c_{2}$.

\begin{tabular}{|c|c|c|c|c|c|c|c|c|c|c|c|c|}
\hline \multirow{2}{*}{ Problem \# } & \multirow{2}{*}{$c_{2}$} & \multicolumn{4}{|c|}{$\begin{array}{c}\text { Absence of } \\
\text { cooperative advertising }\end{array}$} & \multicolumn{4}{|c|}{$\begin{array}{c}\text { Presence of } \\
\text { cooperative advertising }\end{array}$} & \multicolumn{3}{|c|}{ Improvement (\%) } \\
\hline & & Eq. & $\Pi_{1}$ & $\Pi_{2}$ & $\Pi_{m}$ & Eq. & $\Pi_{1}$ & $\Pi_{2}$ & $\Pi_{m}$ & $\Pi_{1}$ & $\Pi_{2}$ & $\Pi_{m}$ \\
\hline 11 & 15 & $(T, T)$ & 6042 & 7000 & 23333 & $(T, T)$ & 16771 & 20000 & 48135 & 178 & 186 & 106 \\
\hline 12 & 25 & $(T, T)$ & 4625 & 5400 & 16000 & $(T, T)$ & 11063 & 13200 & 30881 & 139 & 144 & 93 \\
\hline 13 & 35 & $(T, T)$ & 4018 & 4714 & 12857 & $(T, T)$ & 8616 & 10286 & 23487 & 114 & 118 & 83 \\
\hline 14 & 45 & $(T, T)$ & 3681 & 4333 & 11111 & $(T, T)$ & 7257 & 8667 & 19378 & 97 & 100 & 74 \\
\hline 15 & 55 & $(T, T)$ & 3466 & 4091 & 10000 & $(T, T)$ & 6392 & 7636 & 16764 & 84 & 87 & 68 \\
\hline 16 & 65 & $(T, T)$ & 3317 & 3923 & 9231 & $(T, T)$ & 5793 & 6923 & 14954 & 75 & 76 & 62 \\
\hline 17 & 75 & $(T, T)$ & 3208 & 3800 & 8667 & $(T, T)$ & 5354 & 6400 & 13627 & 67 & 68 & 57 \\
\hline 18 & 85 & $(T, T)$ & 3125 & 3706 & 8235 & $(T, T)$ & 5018 & 6000 & 12612 & 61 & 62 & 53 \\
\hline 19 & 95 & $(T, T)$ & 3059 & 3632 & 7895 & $(T, T)$ & 4753 & 5684 & 11811 & 55 & 56 & 50 \\
\hline 20 & 105 & $(T, T)$ & 3006 & 3571 & 7619 & $(T, T)$ & 4539 & 5429 & 11162 & 51 & 52 & 47 \\
\hline
\end{tabular}

Table 8. Changes in variables with regard to changes in $c_{2}$.

\begin{tabular}{|c|c|c|c|c|c|c|c|c|c|}
\hline \multirow{2}{*}{ Problem \# } & \multirow{2}{*}{$c_{2}$} & \multicolumn{3}{|c|}{$\begin{array}{c}\text { Absence of } \\
\text { cooperative advertising }\end{array}$} & \multicolumn{5}{|c|}{$\begin{array}{c}\text { Presence of } \\
\text { cooperative advertising }\end{array}$} \\
\hline & & $A$ & $a$ & $b$ & $t_{1}$ & $t_{2}$ & $A$ & $a$ & $b$ \\
\hline 11 & 15 & 25 & 69.4 & 100 & 0.78 & 0.74 & 25 & 1406.3 & 1469.4 \\
\hline 12 & 25 & 25 & 25 & 36 & 0.78 & 0.74 & 25 & 506.3 & 529 \\
\hline 13 & 35 & 25 & 12.8 & 18.4 & 0.78 & 0.74 & 25 & 258.3 & 269.9 \\
\hline 14 & 45 & 25 & 7.7 & 11.1 & 0.78 & 0.74 & 25 & 156.3 & 163.3 \\
\hline 15 & 55 & 25 & 5.2 & 7.4 & 0.78 & 0.74 & 25 & 104.6 & 109.3 \\
\hline 16 & 65 & 25 & 3.7 & 5.3 & 0.78 & 0.74 & 25 & 74.9 & 78.3 \\
\hline 17 & 75 & 25 & 2.8 & 4 & 0.78 & 0.74 & 25 & 56.3 & 58.8 \\
\hline 18 & 85 & 25 & 2.2 & 3.1 & 0.78 & 0.74 & 25 & 43.8 & 45.8 \\
\hline 19 & 95 & 25 & 1.7 & 2.5 & 0.78 & 0.74 & 25 & 35.1 & 36.6 \\
\hline 20 & 105 & 25 & 1.4 & 2 & 0.78 & 0.74 & 25 & 28.7 & 30 \\
\hline
\end{tabular}

Table 9. Changes in profits with regard to changes in $k_{2}$.

\begin{tabular}{|c|c|c|c|c|c|c|c|c|c|c|c|c|}
\hline \multirow{2}{*}{ Problem \# } & \multirow{2}{*}{$k_{2}$} & \multicolumn{4}{|c|}{$\begin{array}{c}\text { Absence of } \\
\text { cooperative advertising }\end{array}$} & \multicolumn{4}{|c|}{$\begin{array}{c}\text { Presence of } \\
\text { cooperative advertising }\end{array}$} & \multicolumn{3}{|c|}{ Improvement (\%) } \\
\hline & & Eq. & $\Pi_{1}$ & $\Pi_{2}$ & $\Pi_{m}$ & Eq. & $\Pi_{1}$ & $\Pi_{2}$ & $\Pi_{m}$ & $\Pi_{1}$ & $\Pi_{2}$ & $\Pi_{m}$ \\
\hline 21 & 25 & $(T, T)$ & 2633 & 3150 & 5688 & $(R, R)$ & 7067 & 8440 & 18803 & 168 & 168 & 231 \\
\hline 22 & 30 & $(T, T)$ & 2691 & 3216 & 5990 & $(R, R)$ & 7067 & 8440 & 18803 & 163 & 162 & 214 \\
\hline 23 & 35 & $(T, T)$ & 2760 & 3294 & 6348 & $(R, R)$ & 7067 & 8440 & 18803 & 156 & 156 & 196 \\
\hline 24 & 40 & $(T, T)$ & 2840 & 3384 & 6760 & $(R, T)$ & 3929 & 8504 & 13681 & 38 & 151 & 102 \\
\hline 25 & 45 & $(T, T)$ & 2930 & 3486 & 7228 & $(T, T)$ & 4234 & 5066 & 10241 & 45 & 45 & 42 \\
\hline 26 & 50 & $(T, T)$ & 3031 & 3600 & 7750 & $(T, T)$ & 4641 & 5550 & 11470 & 53 & 54 & 48 \\
\hline 27 & 55 & $(T, T)$ & 3143 & 3726 & 8328 & $(T, T)$ & 5090 & 6086 & 12829 & 62 & 63 & 54 \\
\hline 28 & 60 & $(T, T)$ & 3265 & 3864 & 8960 & $(T, T)$ & 5583 & 6672 & 14317 & 71 & 73 & 60 \\
\hline 29 & 65 & $(T, T)$ & 3398 & 4014 & 9648 & $(T, T)$ & 6118 & 7310 & 15935 & 80 & 82 & 65 \\
\hline 30 & 70 & $(T, T)$ & 3541 & 4176 & 10390 & $(T, T)$ & 6696 & 7998 & 17682 & 89 & 92 & 70 \\
\hline
\end{tabular}


Table 10. Changes In variables with regard to changes in $k_{2}$.

\begin{tabular}{|c|c|c|c|c|c|c|c|c|c|}
\hline \multirow{2}{*}{ Problem \# } & \multirow{2}{*}{$k_{2}$} & \multicolumn{3}{|c|}{$\begin{array}{c}\text { Absence of } \\
\text { cooperative advertising }\end{array}$} & \multicolumn{5}{|c|}{$\begin{array}{c}\text { Presence of } \\
\text { cooperative advertising }\end{array}$} \\
\hline & & $A$ & $a$ & $b$ & $t_{1}$ & $t_{2}$ & $A$ & $a$ & $b$ \\
\hline 21 & 25 & 25 & 0.4 & 0.6 & 0.78 & 0.74 & 25 & 225 & 235.1 \\
\hline 22 & 30 & 25 & 0.6 & 0.8 & 0.78 & 0.74 & 25 & 225 & 235.1 \\
\hline 23 & 35 & 25 & 0.8 & 1.1 & 0.78 & 0.74 & 25 & 225 & 235.1 \\
\hline 24 & 40 & 25 & 1 & 1.4 & 0.82 & 0.69 & 25 & 215.1 & 22.3 \\
\hline 25 & 45 & 25 & 1.3 & 1.8 & 0.78 & 0.74 & 25 & 25.6 & 26.8 \\
\hline 26 & 50 & 25 & 1.6 & 2.3 & 0.78 & 0.74 & 25 & 31.6 & 33.1 \\
\hline 27 & 55 & 25 & 1.9 & 2.7 & 0.78 & 0.74 & 25 & 38.3 & 40 \\
\hline 28 & 60 & 25 & 2.3 & 3.2 & 0.78 & 0.74 & 25 & 45.6 & 47.6 \\
\hline 29 & 65 & 25 & 2.6 & 3.8 & 0.78 & 0.74 & 25 & 53.5 & 55.9 \\
\hline 30 & 70 & 25 & 3.1 & 4.4 & 0.78 & 0.74 & 25 & 62 & 64.8 \\
\hline
\end{tabular}

Table 11. Discrete values of parameters for analyzing a win-win condition.

\begin{tabular}{cl}
\hline Parameter & \multicolumn{1}{c}{ Discrete values } \\
\hline$\rho_{m}$ & $(15,16, \cdots, 25)$ \\
$\rho_{1}$ & $(5,6, \cdots, 15)$ \\
$\rho_{2}$ & $(7,8, \cdots, 17)$ \\
$k_{m}$ & $(75,76, \cdots, 125)$ \\
$k_{1}$ & $(30,31, \cdots, 50)$ \\
$k_{2}$ & $\left(k_{1}, k_{1+1}, \cdots, 80\right)$ \\
$C$ & $(150,151, \cdots, 250)$ \\
$c_{1}$ & $(20,21, \cdots, 40)$ \\
$c_{2}$ & $\left(c_{1}, c_{1}+1, \cdots, 150\right)$ \\
$\eta$ & $(0.01,0.02, \cdots, 0.49)$ \\
\hline
\end{tabular}

\subsection{Sensitivity analysis of win-win condition}

As shown in Example 1, offering contract improves the profits of members. This result is still valid when only one parameter changes, and the rest will stay constant. In this section, this topic is examined for different combinations of parameters. Since this analysis is not analytically possible, discrete values are assigned to the parameters. Then, the analysis is performed to simultaneously change some combinations of parameters. Of note, the parameter values can change in the ranges given in Table 11.

Without loss of generality, it is assumed that the 2nd advertising option is more efficient and it costs more than the 1 st one. Therefore, we always have $c_{2} \geq c_{1}$ and $k_{2} \geq k_{1}$. This is true in the real world for television and radio advertising. It should be noted that $c_{2}$ starts from $c_{1}$ and $k_{2}$ starts from $k_{1}$. As mentioned earlier, for game $G(\eta), \eta$ is the market share of retailer 1 for outcome $(R, T)$ that cannot be greater than 0.5 , considering the efficiency of advertising options.
To analyze the sensitivity of the win-win condition, simultaneous changes of two or three parameters are examined in each run. Then, it is examined whether or not offering the contract improves the profits of all members. For example, to examine the simultaneous changes of $\eta$ and $\rho_{1}$, the problem is solved for all possible combinations between these two parameters. Since we have $\eta \in(0.01,0.02, \cdots, 0.49)$ and $\rho_{1} \in(5,6, \cdots, 15)$, we need to solve the problem $49 \times 11=539$ times. It should also be noted that when simultaneously checking two or three parameters, the values for other parameters are set in accordance with their base value in Example 1.

The results of sensitivity analysis are as follows:

- Offering the contract improves the profits of all members when any pair of parameters in Table 9 simultaneously change. Since we have 10 parameters, there are a total of 45 possible pairs of parameters;

- To evaluate the simultaneous changes in the values of three parameters, we run the problem for some combination of parameters. According to the results, offering the contract improves the profits of all members for the following combinations of the parameters:

$$
\left\{\begin{array}{l}
\left\{\eta, \rho_{1}, \rho_{2}\right\},\left\{\eta, \rho_{1}, \rho_{m}\right\},\left\{\eta, \rho_{2}, \rho_{m}\right\}, \\
\left\{\eta, c_{1}, c_{2}\right\},\left\{\eta, c_{1}, C\right\},\left\{\eta, c_{2}, C\right\}, \\
\left\{\eta, k_{1}, k_{2}\right\},\left\{\eta, k_{1}, k_{m}\right\},\left\{\eta, k_{2}, k_{m}\right\}, \\
\left\{\eta, k_{2}, c_{2}\right\}
\end{array}\right\} .
$$

For further analysis of the win-win condition, sensitivity analysis is performed on Example 2.

Figure 2(a) shows the results obtained from changes in $\eta$ and $k_{2}$. The determined area is outside the win-win condition where at least one member is worse 


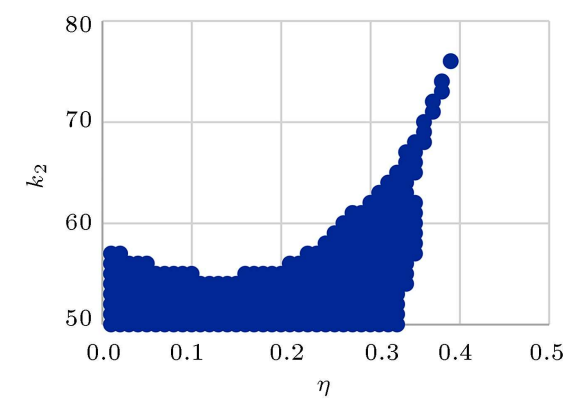

(a)

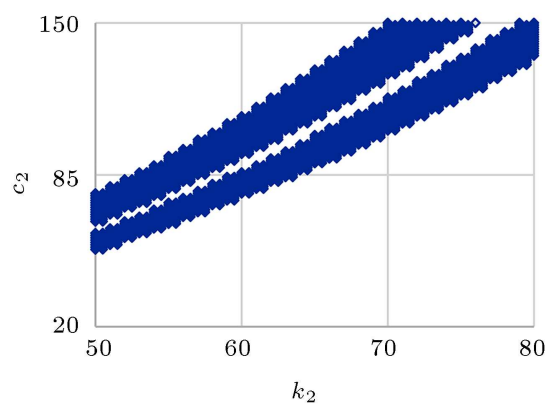

(c)

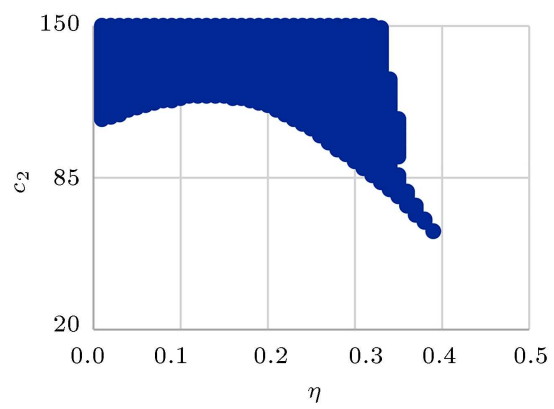

(b)

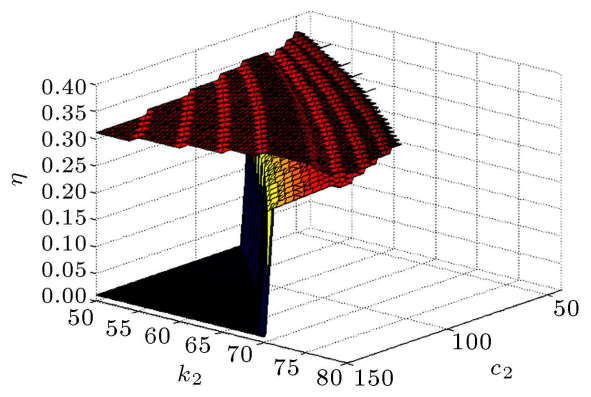

(d)

Figure 2. The area (space) outside the win-win condition according to changes in (a) $\eta$ and $k_{2}$, (b) $\eta$ and $c_{2}$, (c) $c_{2}$, and $k_{2}$, and (d) $\eta, c_{2}$, and $k_{2}$.

off by offering the contract. It is reasonable for the manufacturer to offer the contract only in the win-win condition. Figure 2(b) shows the results of changes in $\eta$ and $c_{2}$, and Figure 2(c) presents the result of changes in $c_{2}$ and $k_{2}$. Figure $2(\mathrm{~d})$ lists the results obtained based on changes in $\eta, c_{2}$, and $k_{2}$. The determined space between two surfaces is outside the win-win condition.

\section{Conclusion}

When advertising the expenditures of the supply chain players directly affects the market demand, cooperative advertising program might be an incentive mechanism proposed by manufacturers to motivate retailers to invest more on local advertising. This paper investigates the cooperative advertising problem in a channel including a manufacturer and two retailers. The current paper extended the previous works in three directions. First, the cooperative advertising problem with two local advertising options was considered. Second, the retailers competed to get a greater market share. Third, two cases of the presence and absence of cooperative advertising were compared to identify win-win conditions. The aforementioned problem was analyzed as a non-cooperative three-stage game using backward induction. The problem was then solved in two cases of the presence and absence of the cooperative advertising contract using illustrative examples and sensitivity analysis. The results indicate that in the case of meeting certain conditions, proposing a cooperative advertising contract was regarded as winwin for all players. There were some possible directions for further research. For example, some extension can be made by considering inventory decisions [46] and multiple performance measures of the supply chain [6], which apparently have almost been neglected in cooperative advertising literature so far. Moreover, some limitations of the current study can be relaxed. Firstly, since the cooperative advertising program does not always lead to a win-win condition, another hybrid mechanism should be proposed. Secondly, another extension can be made to a situation without the exchange of information between retailers.

\section{References}

1. Arshinder, K., Kanda, A., and Deshmukh, S.G. "A review on supply chain coordination: coordination mechanisms, managing uncertainty and research directions", In Supply Chain Coordination under Uncertainty, T.M. Choi, T.C.E. Cheng, Eds. pp. 39-82, Springer-Verlag, Berlin Heidelberg (2011).

2. Lee, H.L. "Creating value through supply chain integration", Supply Chain Manag. Rev., 4(4), pp. 30-36 (2000).

3. Alaei, S., Behravesh, M., and Karegar, N. "Analysis of production-inventory decisions in a decentralized supply chain", Prague Econ. Pap., 23(2), pp. 198-121 (2014).

4. Wu, D. "Coordination of competing supply chains with 
news-vendor and buyback contract", Int. J. of Prod. Econ., 144(1), pp. 1-13 (2013).

5. Alaei, S. and Setak, M. "Multi objective coordination of a supply chain with routing and service level consideration", Int. J. of Prod. Econ., 167, pp. 271-281 (2015).

6. Alaei, S. and Khoshalhan, F. "A hybrid culturalharmony algorithm for multi-objective supply chain coordination", Sci. Iran. E, 22(3), pp. 1227-1241 (2015).

7. Berger, P.D. "Vertical cooperative advertising ventures", J. of Marketing Res., 9(3), pp. 309-312 (1972).

8. Huang, Z. and Li, S.X. "Co-op advertising models in manufacturer-retailer supply chains: A game theory approach", Eur. J. of Oper. Res., 135(3), pp. 527-544 (2001).

9. Bergen, M. and John, G. "Understanding cooperative advertising participation rates in conventional channels", J. of Marketing Res., 34(3), pp. 357-369 (1997).

10. Zhang, J., Xie, J., and Chen, B. "Cooperative advertising with bilateral participation", Dec. Sci., 44(1), pp. 193-203 (2013).

11. Chakraborty, T., Chauhan, S.S., and Vidyarthi, N. "Coordination and competition in a common retailer channel: Wholesale price versus revenue-sharing mechanisms", Int. J. of Prod. Econ., 166, pp. 103-118 (2015).

12. Lieb, R. "Co-op advertising: Digital's lost ppportunity?", Report, Interactive Advertising Bureau, Local Search Association (2012).

13. Hutchins, M.S., Cooperative Advertising; The Way to Make It Pay, New York: Ronald Press (1953).

14. Herrington, J.D. and Dempsey, W.A. "Comparing the current effects and carryover of national-, regionaland local-sponsor advertising", J. of Advertising Res., 45(1), pp. 60-72 (2005).

15. Somers, T.M., Gupta, Y.P., and Harriot, S.R. "Analysis of cooperative advertising expenditures: A transferfunction modeling approach", J. of Advertising Res., 30(5), pp. 35-49 (1990).

16. Young, R.F. and Greyser, S.A., Managing cooperative Advertising: A Strategic Approach, Lexington, MA: Lexington Books (1983).

17. Elkin, T. "Co-op crossroads", Advertising Age, 70(47), pp. 1-4 (1999).

18. Brennan, L. "How retailers are putting it all together?", Sales and Mark. Manag., 5, pp. 62-65 (1988).

19. Clark, S. "Dual destiny", Adweek, 41, pp. 60-66 (2000).

20. Nagler, M.G. "An exploratory analysis of the determinants of cooperative advertising participation rates", Market. Lett., 17(2), pp. 91-102 (2006).
21. Xie, J. and Wei, J.C. "Coordinating advertising and pricing in a manufacturer-retailer channel", Eur. J. of Oper. Res., 197(2), pp. 785-791 (2009).

22. Aust, G. and Buscher, U. "Vertical cooperative advertising and pricing decisions in a manufacturer-retailer supply chain: A game-theoretic approach", Eur. J. of Oper. Res., 223(2), pp. 473-482 (2012).

23. Alaei, S., Alaei, R., and Salimi, P. "A game theoretical study of cooperative advertising in a singlemanufacturer-two-retailers supply chain", Int. J. of Adv. Manuf. Tech., 74(1-4), pp. 101-111 (2014).

24. Tsao, Y.C. "Cooperative promotion under demand uncertainty", Int. J. of Prod. Econ., 167, pp. 45-49 (2015).

25. Aust, G. and Buscher, U. "Cooperative advertising models in supply chain management: A review", Eur. J. of Oper. Res., 234, pp. 1-14 (2014).

26. Jørgensen, S. and Zaccour, G. "A survey of gametheoretic models of cooperative advertising", Eur. J. of Oper. Res., 237, pp. 1-14 (2014).

27. Chaeb, J. and Rasti-Barzoki, M. "Cooperative advertising and pricing in a manufacturer-retailer supply chain with a general demand function; A gametheoretic approach", Comput. and Ind. Eng., 99, pp. 112-123 (2016).

28. Alaei, S. and Setak, M. "Supply chain coordination via two-way cooperative advertising contract considering competing retailers", Sci. Iran., E, 23(5), pp. 23302340 (2016).

29. Xu, Q., Xu, B., Bo, Q., et al. "Coordination through cooperative advertising in a two-period supply chain with retail competition", Kybernetes, 48(6), pp. 11751194 (2019).

30. He, Y., Wang, H., Guo, Q., et al. "Coordination through cooperative advertising in a two-period consumer electronics supply chain", J. of Retailing and Cons. Ser., 50, pp. 179-188 (2019).

31. Aust, G. and Buscher, U. "Vertical cooperative advertising in a retailer duopoly", Comput. and Ind. Eng., 72, pp. 247-254 (2014).

32. Setak, M., Kafshian Ahar, H., and Alaei, S. "Incentive mechanism based on cooperative advertising for cost information sharing in a supply chain with competing retailers", J. of Ind. Eng. Int., 14(2), pp. 265-280 (2018).

33. Jørgensen, S. and Zaccour, G. "A differential game of retailer promotions", Automatica, 39(7), pp. 11451155 (2003).

34. Malthouse, E.C., Qiu, D., and Xu, J. "Optimal selection of media vehicles using customer databases", Expert Syst. Appl., 39(17), pp. 13035-13045 (2012). 
35. Frison, S., Dekimpe, M.G., Croux, C., et al. "Billboard and cinema advertising: Missed opportunity or spoiled arms?", Int. J. of Res. Mark., 31(4), pp. 425-433 (2014).

36. Naik, P.A. and Peters, K. "A hierarchical marketing communications model of online and offline media synergies", J. of Interact. Mark., 23(4), pp. 288-299 (2009).

37. Jørgensen, S., Taboubi, S., and Zaccour, G. "Cooperative advertising in a marketing channel", J. of Optimiz. Theory App., 110(1), pp. 145-158 (2001).

38. Yang, J., Xie, J., Deng, X., et al. "Cooperative advertising in a distribution channel with fairness concerns", Eur. J. of Oper. Res., 227(2), pp. 401-407 (2013).

39. Chen, T.H. "Coordinating the ordering and advertising policies for a single-period commodity in a two-level supply chain", Comput. and Ind. Eng., 61(4), pp. 1268-1274 (2011).

40. Giri, B.C. and Bardhan, S. "Note on coordinating the ordering and advertising policies for a single-period commodity in a two-level supply chain", Comput. and Ind. Eng., 77, pp. 11-14 (2014).

41. Gou, Q., Zhang, J., Liang, L., et al. "Horizontal cooperative programmes and cooperative advertising", Int. J. of Prod. Res., 52(3), pp. 691-712 (2014).

42. Karray, S. and Hassanzadeh-Amin, S. "Cooperative advertising in a supply chain with retail competition", Int. J. of Prod. Res., 53(1), pp. 88-105 (2015).

43. Li, S.X., Huang, Z., Zhu, J., et al. "Cooperative advertising, game theory and manufacturer-retailer supply chains", Omega, 30(5), pp. 347-357 (2002).

44. Nash, J.F. "The bargaining problem", Econometrica, 18(2), pp. 155-162 (1950).

45. Von Stackelberg, H., Marktform und Gleichgewicht, Wien und Berlin: J. Springer (1934).

46. Alaei, S., Hajj, A., Alaei, R., et al. "A theoritical game approach for two echelon stochastic inventory system", Acta Polytech. Hung., 12(4), pp. 221-239 (2015).

\section{Appendix A}

To prove that the manufacturer's objective function is concave to variables $A, t_{1}^{i j}$, and $t_{2}^{i j}$ only prove that the given Hessian matrix (A.1) is negative definite:

$$
H=\left[\begin{array}{lll}
\frac{\partial^{2} \Pi_{m \mid(i, j)}}{\partial A^{2}} & \frac{\partial^{2} \Pi_{m \mid(i, j)}}{\partial A \partial t_{1}} & \frac{\partial^{2} \Pi_{m \mid(i, j)}}{\partial A \partial t_{2}} \\
\frac{\partial^{2} \Pi_{m \mid(i, j)}}{\partial t_{1} \partial A} & \frac{\partial^{2} \Pi_{m \mid(i, j)}}{\partial t_{1}^{2}} & \frac{\partial^{2} \Pi_{m \mid(i, j)}}{\partial t_{1} \partial t_{2}} \\
\frac{\partial^{2} \Pi_{m \mid(i, j)}}{\partial t_{2} \partial A} & \frac{\partial^{2} \Pi_{m \mid(i, j)}}{\partial t_{2} \partial t_{1}} & \frac{\partial^{2} \Pi_{m \mid(i, j)}}{\partial t_{2}^{2}}
\end{array}\right] .
$$

It should be noted that in the above relation, superscripts of variables $t_{1}^{i j}$ and $t_{2}^{i j}$ are removed for convenience. Based on Eqs. (10), (11), and (12), the second-order partial derivatives are calculated as follows:

$$
\begin{aligned}
& \frac{\partial^{2} \Pi_{m \mid(i, j)}}{\partial A^{2}}=-\frac{\rho_{m} k_{m}}{4 \sqrt{A^{3}}}, \\
& \frac{\partial^{2} \Pi_{m \mid(i, j)}}{\partial t_{1}^{2}}=\frac{\rho_{1} \eta_{i j} k_{i}^{2}}{c_{i}\left(1-t_{1}\right)^{4}} \\
& \times\left[\left(1-t_{1}\right) \rho_{m}-\left(\frac{2+t_{1}}{2}\right) \rho_{1} \eta_{i j}\right], \\
& \frac{\partial^{2} \Pi_{m \mid(i, j)}}{\partial t_{2}^{2}}=\frac{\rho_{2}\left(1-\eta_{i j}\right) k_{j}^{2}}{c_{j}\left(1-t_{2}\right)^{4}} \\
& \times\left[\left(1-t_{2}\right) \rho_{m}-\left(\frac{2+t_{2}}{2}\right) \rho_{2}\left(1-\eta_{i j}\right)\right] \\
& \frac{\partial^{2} \Pi_{m \mid(i, j)}}{\partial A \partial t_{1}}=0 \\
& \frac{\partial^{2} \Pi_{m \mid(i, j)}}{\partial A \partial t_{2}}=0 \\
& \frac{\partial^{2} \Pi_{m \mid(i, j)}}{\partial t_{1} \partial t_{2}}=0 .
\end{aligned}
$$

Due to the obtained equations (Eqs. (A.2)-(A.7)), the only major diameter of the matrix is nonzero and all other elements are zero. To prove the matrix as negative definite, each element of the diagonal should be proved to be negative.

Eq. (A.2) is always negative and Eq. (A.3) is also negative under the following conditions:

$$
t_{1}^{i j}>t_{1}^{i j}=\frac{2 \rho_{m}-2 \rho_{1} \eta_{i j}}{2 \rho_{m}+\rho_{1} \eta_{i j}} .
$$

Similarly, Eq. (A.4) is negative under the following conditions:

$$
t_{2}^{i j}>t_{2}^{i j}=\frac{2 \rho_{m}-2 \rho_{2}\left(1-\eta_{i j}\right)}{2 \rho_{m}+\rho_{2}\left(1-\eta_{i j}\right)},
$$

where values $t_{1}^{i j}$ and $t_{2}^{\prime i j}$ are threshold values. The above conditions cannot be definitively met, yet clearly, the optimal values of the participation rates in Proposition 2 satisfy the above conditions. Therefore, even though the concavity of the manufacturer's objective function cannot be proved with certainty, as proved earlier, the function is concave around the solution obtained in Proposition 2.

\section{Biographies}

Saeed Alaei obtained MSc and PhD degrees in Industrial Engineering from Sharif University of Technology in 2011 and K.N. Toosi University of Technology in 2017, respectively. Currently, he is an Assistant Professor at Industrial Engineering Department of Khatam 
University, Tehran, Iran. His research interests include OR, supply chain coordination, multi-attribute decision-making, and applied game theory.

Neda Manavizadeh received her MSc in Industrial Engineering at College of Engineering, University of Tehran (2003-2005). She obtained her $\mathrm{PhD}$ in
Industrial Engineering from College of Engineering, University of Tehran (Start year: 2008). Currently, she is an Assistant Professor at Industrial Engineering Department of Khatam University, Tehran, Iran. Her research interests include production planning, supply chain management, operations management, and operations research. 